\title{
ASPECTOS COGNITIVOS E SOCIAIS DO COMPORTAMENTO INFORMACIONAL DOS DESENVOLVEDORES DE SOFTWARE: UMA ANÁLISE DA PRODUÇÃO CIENTÍFICA
}

COGNITIVE AND SOCIAL ASPECTS OF SOFTWARE DEVELOPERS INFORMATION BEHAVIOR: AN ANALYSIS OF THE LITERATURE

'Leonardo Pereira Pinheiro de Souza

${ }^{1}$ Marta Lígia Pomim Valentim

'Daniel Martínez Ávila

Universidade Estadual Paulista ${ }^{1}$

\section{Correspondência}

Leonardo Pereira Pinheiro de Souza

Universidade Estadual Paulista

Marília, SP - Brasil

E-mail: leopinheirodesouza@gmail.com

Submetido em: 04/04/2018

Aceito em: 23/11/2018

Publicado em: 10/12/2018

Checagem antiplágio

turnitind

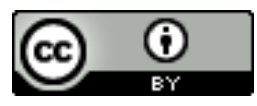

JITA: CB. User studies.

e-Location ID: 019010 
RESUMO

A indústria de software tem papel importante na sociedade, sendo um setor lucrativo que provê centenas de milhares de empregos diretos no Brasil. Os programadores têm especial relevância neste contexto, pois são eles que desenvolvem os programas computacionais, utilizando conhecimentos e informações. Na presente revisão de literatura são abordados aspectos da relação desses profissionais com a informação, ou seja, seu comportamento informacional, suas necessidades e problemas neste respeito. Destaca-se ainda a importância de contextualizar o comportamento informacional no âmbito social, neste caso, evidenciado pela cultura organizacional. Foi ainda verificado se o volume da produção científica sobre o comportamento informacional dos referidos profissionais na Ciência da Informação é condizente com a relevância desse ofício para a sociedade, comparado à produção sobre o comportamento informacional de outros profissionais do conhecimento. Como procedimentos metodológicos, realizou-se uma pesquisa em bases de dados on line apurando a quantidade de trabalhos sobre a referida temática, analisando-se seus resumos para examinar os paradigmas e abordagens adotados. Evidenciouse que poucos trabalhos consideram esta temática na Ciência da Informação, revelando que o tema necessita receber maior atenção no âmbito acadêmico.

\section{PALAVRAS-CHAVE}

Estudo de usuário. Necessidade de Informação. Software.

\section{ABSTRACT}

The software industry plays an important role in the Brazilian society as a profitable sector that employs hundreds of thousands of people. Programmers have special relevance in this context since they develop computational programs using knowledge and information. This literature review addresses the relationship of these professionals with information, i.e., their information behavior, as well as their needs and problems in this regard. We also emphasize the importance of contextualize the informational behavior in the social sphere, in this case, the organizational culture. We studied if the volume of the scientific production on the information behavior of these professionals in Information Science corresponds with the relevance of their profession to the society, compared to the production on the informational behavior of other knowledge professionals. As a methodology, we searched the papers on this subject indexed by online databases, analyzing their abstracts to verify the paradigms and approaches adopted. It is shown that few studies consider this subject in Information Science, revealing the need of more research on this topic.

\section{KEYWORDS}

User Studies. Information Needs. Computer Software. 


\section{RPBOI $\begin{aligned} & \text { Revista Digital Biblioteconomia e Ciência } \\ & \text { da Informação }\end{aligned}$ RPBO $\begin{aligned} & \text { Digital Journal of Library and Information } \\ & \text { Science }\end{aligned}$

\section{INTRODUÇÃO}

A tecnologia se apresenta de maneira ubíqua em quase todos os aspectos da vida contemporânea. Embutidos nos apetrechos tecnológicos encontram-se invariavelmente conjuntos de instruções que determinam seu funcionamento: o software. A relevância do software torna-se ainda mais visível ao se confrontar com a imensidão de dados por eles produzidos e analisados, intensificada com o advento da Internet: o big data, como definem Kaisler et al. (2013). Como destaca a Associação para a Excelência do Software Brasileiro (2015), a indústria de software é altamente lucrativa e fonte de emprego direto para mais de seiscentos mil pessoas no país. Essa indústria é impulsionada justamente pelo trabalho dos desenvolvedores de softwares, ou programadores.

Os profissionais de desenvolvimento de software podem ser classificados como o que Drucker (1999) denomina de trabalhadores do conhecimento, porque o conhecimento e a informação são os principais 'insumos' de sua produção e suas principais 'ferramentas' de trabalho. Desse modo, é de suma relevância compreender como se dá a relação dos desenvolvedores de software (programadores) com a informação, e quais as suas necessidades a este respeito. Nessa perspectiva, apresentam-se os seguintes problemas de pesquisa: quais são as características típicas das necessidades e comportamentos informacionais dos desenvolvedores de software? O volume de produção científica que considera o comportamento informacional dos programadores é condizente com a relevância que seu ofício representa para a sociedade, tal como ocorre com estudos realizados sobre outros trabalhadores do conhecimento, como cientistas e engenheiros?

Para o primeiro problema, apresenta-se a hipótese de que, como os referidos profissionais trabalham imersos em um ambiente tecnológico, a tecnologia tem papel preponderante em seus hábitos de busca de informação, sobrepujando as informações obtidas por intermédio da comunicação com outros seres humanos. Em relação ao segundo problema, a hipótese é que a produção científica sobre o tema é pequena, visto que os programadores não estão entre as categorias profissionais tradicionalmente consideradas nos estudos de usuários da informação, como são os cientistas, engenheiros, profissionais de saúde, entre outros (SPINK; CASE, 2012).

O presente trabalho objetiva expor alguns aspectos da relação dos programadores com a informação, ou seja, seu comportamento informacional, as necessidades e problemas neste respeito, bem como analisar a produção científica sobre o tema no âmbito da Ciência da Informação (CI). Para tanto, verificou-se a quantidade de artigos sobre a referida temática em bases de dados online e analisou-se os resumos dos artigos selecionados, verificando elementos 


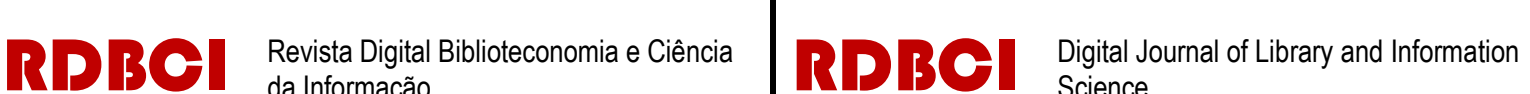

que denotam um exame efetivo do comportamento e das necessidades informacionais dos referidos profissionais.

A perspectiva de comportamento informacional aqui considerada é centrada no ser humano, considerando os aspectos contextuais e sociais da busca e uso da informação, isto é, o ambiente de trabalho que circunda os profissionais. Essa perspectiva é coerente com a constatação de Davenport e Prusak (1998) de que o emprego da tecnologia não basta para um uso eficaz da informação, mas é necessário considerar os fatores humanos envolvidos e o ambiente informacional da organização. Esta visão concorda também com o fato exposto por Salovaara e Tuunainen (2013), de que os projetos de software são comumente executados em equipes auto-organizadas, denotando que cada membro executa um papel específico e, ao mesmo tempo, colabora com a coesão do grupo e com o sucesso do projeto de software como um todo. O presente trabalho não pretende se pautar em uma compreensão apenas tecnológica, mas sim valorizar a inteligência humana, que efetivamente comanda a máquina.

\section{A AVALANCHE INFORMACIONAL E A TECNOLOGIA DA INFORMAÇÃO}

$\mathrm{Na}$ contemporaneidade existe uma disponibilidade sem precedentes de informações e conhecimentos, que são cada vez mais imprescindíveis para o desenvolvimento das organizações e das sociedades como um todo. Drucker (1999) discorre sobre uma Sociedade do Conhecimento, não muito distante da Era do 'Pós-Capitalismo', em que o conhecimento, não o capital ou as terras, seria a viga mestra da economia, um mundo onde não mais existiria a dicotomia entre o patrão e o trabalhador dele dependente. No cenário idílico deste autor, o trabalhador detentor do conhecimento, o novo 'meio de produção', seria quase autossuficiente, podendo transitar livremente de uma empresa à outra, de um empregador a outro, conforme sua conveniência. Embora essa sociedade onírica pareça ainda estar longe de se concretizar do modo descrito anteriormente, pela constatação das realidades econômica e social contemporâneas, pode-se afirmar que o conhecimento tem cada vez mais relevância econômica. Drucker (1999) menciona um acontecimento emblemático dessa orientação para o conhecimento, a elaboração da Declaração de Direitos dos Combatentes Americanos, por meio da qual o governo estadunidense passou a financiar a educação superior dos soldados que regressavam da Segunda Guerra Mundial.

Intimamente ligada ao conhecimento está a informação, considerada a unidade básica de sua construção. Conforme Spink e Case (2012), informação pode designar qualquer diferença percebida no próprio indivíduo ou no ambiente que o cerca, na realidade em que está inserido. Evidentemente, essa definição não é nem absoluta nem inquestionável. A informação é um elemento tão onipresente na existência humana, e que se mostra em tão variadas formas, que é difícil defini-la inquestionavelmente. Para Gleick (2013, p.4) “[...] a informação é aquilo que alimenta o funcionamento do nosso mundo: o sangue e o combustível, o princípio vital. Ela

\begin{tabular}{l|l|l|l|l|l}
\hline (๖) RDBCl: Rev. Digit. Bibliotecon. Cienc. Inf. & Campinas, SP & v.17 & $1-27$ & e019010 & 2018 \\
\hline
\end{tabular}




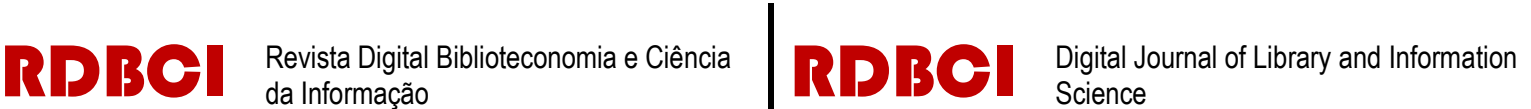

permeia a Ciência de cima a baixo, transformando todos os ramos do conhecimento". No presente trabalho, o conceito de informação empregado é o chamado "conceito ainda mais amplo' elaborado por Saracevic (1999). Segundo o autor, esse conceito determina a informação como uma mensagem processada cognitivamente e contextualizada por meio da situação, do problema em mãos e outros contextos. Tendo sido discutido o papel da informação e do conhecimento no mundo contemporâneo, é pertinente fazer ainda uma contextualização histórica que, por sua vez, servirá para elucidar brevemente as raízes da 'avalanche' informacional vigente e as estratégias elaboradas para mitigá-la.

\subsection{O Advento dos Computadores e da Ciência da Informação}

A denominada 'explosão informacional' é uma situação que tem afligido a sociedade por mais de meio século. Bush (1945) já se preocupava, no momento imediato após o fim da Segunda Guerra Mundial, com o montante gigantesco de informações produzidas até então, intensificado com o papel central desempenhado pela Ciência no esforço de guerra. Era então necessário empregar todas essas informações e conhecimentos da melhor maneira possível, fazê-los gerar desenvolvimento e riqueza. O autor supracitado ponderava, em 1945, que se naquela época vários aspectos da vida e do trabalho já haviam sido afetados pela tecnologia, era necessário encontrar um meio de usá-la também para tornar mais eficaz a relação do ser humano com a informação. É nesse contexto que se dá a gênese da CI, que nas décadas iniciais se preocupava em prover informações de boa qualidade aos cientistas, sendo também alcunhada de Ciência da Informação Científica, segundo Araújo (2014).

Não demorou muito para que uma solução fosse apresentada para o problema da informação. Gleick (2013) menciona que o matemático inglês Alan Turing elaborou um conceito de máquina 'pensante', apresentado em 1936. Conforme este autor, a referida máquina seria capaz de ler um conjunto de símbolos, representados por sequências de zeros e uns, e, conforme o estado ou configuração, em que se encontrasse no momento da leitura, realizaria uma operação de acordo com o símbolo de entrada. Os conceitos da máquina de Turing são, até hoje, os princípios básicos que regem o funcionamento dos computadores. Ainda, segundo Gleick (2013), no final da Segunda Guerra mundial, surgiram os primeiros computadores eletrônicos, como o Electronic Numerical Integrator and Computer (ENIAC), movido a válvulas termiônicas de vinte e cinco metros de extensão.

Gradativamente, os computadores passaram a desenvolver capacidades além da realização de cálculos complexos, objetivo para o qual foram originalmente construídos. Essas máquinas passaram a ser ferramentas imprescindíveis para o gerenciamento de um grande volume de informações, como vislumbrado por Bush (1945). Embora, segundo Gleick (2013), Alan Turing e seu colega Claude Shannon, discutissem, a possibilidade de uma máquina verdadeiramente pensante, que pudesse compreender elementos culturais, como a música, até

\begin{tabular}{l|l|l|l|l|l}
\hline (c) RDBCl: Rev. Digit. Bibliotecon. Cienc. Inf. & Campinas, SP & v.17 & $1-27$ & e019010 & 2018 \\
\hline
\end{tabular}




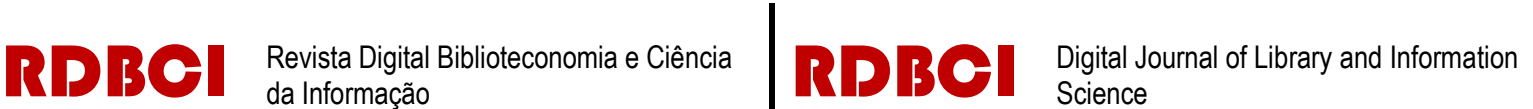

o presente, o computador não desenvolveu autonomia para verdadeiramente pensar. Como se pode evidenciar na análise da máquina de Turing, o computador trabalha mediante um conjunto de instruções detalhadas, previamente programadas: o software. Assim, mostra-se necessário discorrer sucintamente sobre a atual indústria de software e sua relevância.

\subsection{A Indústria de Software e seu Impacto na Sociedade}

A indústria de software tem grande relevância econômica em termos mundiais, gerando lucros vultuosos para seus países produtores. Um exemplo dessa pujança foi a compra da rede social para profissionais, LinkedIn, pela empresa Microsoft, por uma soma de vinte e seis bilhões de dólares americanos, em 2016, segundo Johnston (2016). Apenas no Brasil, segundo a Associação para a Excelência do Software Brasileiro (2015), essa indústria gera cerca de cento e dez bilhões de dólares anualmente.

A presença dos computadores no âmbito empresarial tem sido relevante para o aumento da eficiência dos processos organizacionais, desde o seu advento. No entanto, com a popularização da Internet e das redes sociais, o impacto do software tomou uma nova dimensão que, auxilia não só no gerenciamento da informação existente, mas gera novas informações em grande volume, a uma velocidade indescritível. A esta nova avalanche de informações se dá o nome de 'Big Data', que pode ser definido como “[...] um montante de dados justamente além da capacidade da tecnologia de armazenar, gerenciar e processar eficientemente" (KAISLER et al., 2013, p. 995, tradução nossa).

A sobrecarga de informações pode se constituir um problema crônico para a organização, ou uma oportunidade, se esta obtiver os meios para tirar vantagem dessa situação. Esse amontoado amorfo de informações, proveniente de várias fontes, pode ser bastante útil para as organizações, quando organizado de maneira coerente. Erevelles, Fukawa e Swayne (2016) afirmam que as organizações podem vantajosamente utilizar ferramentas de análise, de modo a identificar padrões ocultos de comportamentos dos consumidores que possam ser úteis no campo estratégico. Pela segunda vez após a constatação de Bush (1945) sobre o montante não gerenciável de informações no pós-guerra, o aspecto informacional se torna novamente um desafio para a sociedade, e novamente a tecnologia propõe suas soluções. Esta situação se configura em uma espécie de ciclo, em que a tecnologia cria soluções para problemas informacionais que, por sua vez, gera novos problemas que são mitigados com novas soluções tecnológicas.

Por mais fascinante que seja a informática, o ser humano ainda possui papel imprescindível em operar as ferramentas tecnológicas e, evidentemente, desenvolvê-las. Nos bastidores deste ofuscante espetáculo encontra-se um imenso contingente de trabalhadores do conhecimento: programadores, analistas de sistemas, gestores de bancos de dados, designers

\begin{tabular}{l|l|l|l|l|l|}
\hline (C) RDBCl: Rev. Digit. Bibliotecon. Cienc. Inf. & Campinas, SP & v.17 & $1-27$ & e019010 & 2018 \\
\hline
\end{tabular}




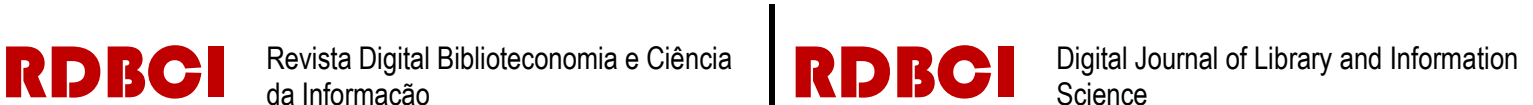

de interfaces gráficas e afins. A indústria de software, portanto, está alicerçada nesses trabalhadores que fazem da informação e do conhecimento a 'matéria-prima' para o desenvolvimento do software. Assim, é premente conhecer como se dá a relação desses profissionais com a informação, uma vez que esta ocupa espaço central em sua atividade.

\section{ESTUDOS DE USUÁRIOS E COMPORTAMENTO INFORMACIONAL}

A relação do indivíduo ou de uma coletividade com a informação se denomina 'comportamento informacional'. Para Spink e Case (2012) o comportamento informacional se refere tanto à busca proposital de informação, a evitação da informação, o recebimento passivo de informação, quanto a situações não intencionais como deparar-se com uma informação. Estes autores evidenciam que o comportamento informacional não se restringe ao âmbito laboral, mas ocorre também em várias situações cotidianas, como, por exemplo, na decisão sobre a compra de um determinado produto.

Wilson (1999) afirma que o comportamento informacional é a manifestação visível da busca de satisfação de uma necessidade informacional. Para este autor, a necessidade informacional visa, em última instância, a satisfação de necessidades básicas a ela subjacentes: fisiológicas, afetivas e/ou cognitivas. No âmbito do trabalho, a necessidade mais premente é a cognitiva, porquanto o indivíduo percebe quando se depara com uma situação para qual o seu conhecimento atual é insuficiente para resolver. Inicia-se então o processo de busca de informação que é uma das manifestações do comportamento informacional.

É importante considerar o comportamento informacional, porque além de ser componente inextricável do trabalho, ele pode ser também aliado do sucesso organizacional, se bem gerenciado. Marchand, Kettinger e Rollins (2001) analisaram uma amostra de vinte e duas empresas, públicas e privadas, de diversos países, e elaboraram um conceito para o que se poderia considerar universalmente como 'bom desempenho organizacional'. Esta é uma perspectiva que vai além do simples aspecto financeiro. Para estes autores, o bom desempenho organizacional é representado pelo crescimento da fatia de mercado, crescimento financeiro, inovação em produtos e serviços, além do atingimento de um nível superior de boa reputação pela empresa. O modelo é coerente, pois infere-se que uma empresa que oferece exatamente o mesmo produto, com a mesma embalagem ao longo de muitos anos ou, ainda, uma empresa conhecida por se envolver em práticas antiéticas, fatalmente podem perder sua fatia de mercado, tendo seus ganhos financeiros prejudicados. Ainda, segundo os autores supracitados, o desempenho superior é atingido por meio do uso eficiente de informação, alinhado a uma boa infraestrutura de tecnologia da informação (TI), com práticas de gestão da informação e um comportamento informacional eficaz. 


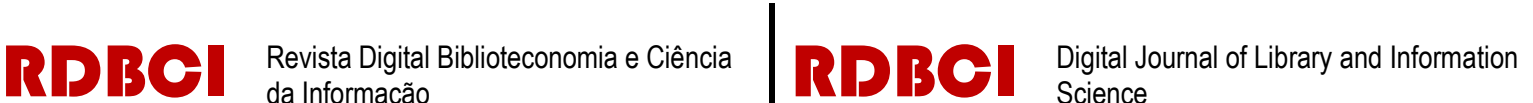

\subsection{Os Paradigmas dos Estudos de Usuário}

Para melhor compreender o comportamento informacional é necessário contextualizá-lo diante das correntes teóricas representadas pelos paradigmas de estudos de usuários da informação. Pode-se compreender que os paradigmas são perspectivas, conjuntos coerentes de teorias, metodologias, conceitos, que servem como um guia para o estudo de uma dada realidade. Kuhn (1998, p.13) explica: “Considero 'paradigmas' as realizações científicas universalmente reconhecidas que, durante algum tempo, fornecem problemas e soluções modelares para uma comunidade de praticantes de uma ciência".

Capurro (2007) classifica os paradigmas da CI em físico - considera a informação como 'coisa mensurável'; cognitivo - enfatiza o conhecimento como entidade independente do aspecto físico, abrindo espaço para abordagens de cunho psicológico; e social - contextualiza a informação nos valores coletivos, como a cultura e a história. O paradigma físico está ligado a uma visão tecnocêntrica, estatística, da informação, como afirma o autor (2003). Os aspectos cognitivo e social da informação, portanto, não recebem grande relevância nessa perspectiva.

O paradigma cognitivo requer uma explicação um pouco mais consistente. Para o autor supracitado, este paradigma pode ser explicado pela epistemologia popperiana dos três mundos, focada, especificamente, no mundo três.

\footnotetext{
[...] podemos distinguir os três mundos ou universos seguintes: o primeiro, o mundo de objetos físicos ou de estados materiais; segundo, o mundo de estados de consciência ou de estados mentais, ou talvez de disposições comportamentais para agir; e, terceiro, o mundo de conteúdos objetivos de pensamento, especialmente de pensamentos científicos e poéticos e de obras de arte (POPPER, 1975, p.108).
}

O terceiro mundo de Popper possibilita compreender a informação e o conhecimento como realidades dotadas de existência própria, independentemente de seus suportes físicos. De fato, Capurro (2007) relaciona esse terceiro mundo com os conteúdos intelectuais das obras escritas, ou seja, a essência do pensamento, independentemente da matéria. Segundo este autor, essa perspectiva da imaterialidade da informação e do conhecimento propiciou considerá-los sob o aspecto cognitivo.

Utilizando-se da classificação de Capurro (2007), Araújo (2010) expõe uma classificação dos paradigmas dos estudos de usuários: a abordagem tradicional, correlata ao paradigma físico; a abordagem alternativa, correlata ao paradigma cognitivo; e o paradigma social, correlato ao seu homônimo. Segundo Araújo (2010), a abordagem tradicional enxerga a informação como tendo propriedades objetivas, visando a avaliação de serviços de informação. Essa abordagem, todavia, apresentava certas lacunas. Para Capurro (2007), o paradigma físico estava voltado à recuperação da informação científica, mas não contemplava os aspectos semântico referente ao sentido, nem o pragmático referente a eficácia da

\begin{tabular}{c|c|c|c|c|c}
\hline (c) RDBCl: Rev. Digit. Bibliotecon. Cienc. Inf. & Campinas, SP & v.17 & $1-27$ & e019010 & 2018 \\
\hline
\end{tabular}




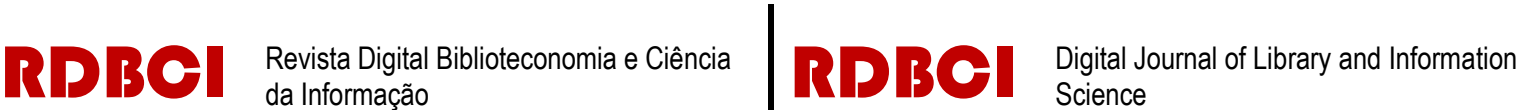

informação. Assim, a abordagem alternativa supre as carências da abordagem anterior, com uma perspectiva centrada no ser humano enquanto indivíduo.

Para Rocha, Paula e Duarte (2016), na Década de 1970, a abordagem alternativa considerava que o indivíduo apenas incorporava informações para suprir lacunas de conhecimentos. Segundo estes autores, ignorava-se a possibilidade de construir conhecimentos na vivência cotidiana, bem como a importância do contexto sociocultural. Capurro (2007) critica o isolacionismo do paradigma cognitivo, correlato à abordagem alternativa, na qual o usuário é visto como absorto nos meandros da própria subjetividade na sua relação com a informação.

O paradigma social vem, posteriormente, com intuito de suprir as carências supramencionadas. No próprio âmbito da abordagem alternativa, porém, foram feitos esforços para romper o cognitivismo estrito. Os autores supracitados mencionam o Information Search Process de Kuhlthau (2005), que, além de considerar a cognição, adicionou também o fator emocional à busca de informação. Outro exemplo é o modelo de Wilson (1999) que, embora mantenha o foco no indivíduo, considera os aspectos demográficos, sociais e situacionais da relação da pessoa com a informação. O modelo de Wilson (1999) é emblemático dessa evolução rumo a uma compreensão de cognição não reducionista, visto que considera que os comportamentos de busca e uso da informação não ocorrem no vácuo, mas estão contextualizados nos aspectos da vida cotidiana, do trabalho, da economia, da política, entre outros. O foco do modelo mencionado, no entanto, continua sendo o indivíduo.

Como afirma Capurro (2007), o paradigma social emergiu com intuito de efetivamente examinar com mais profundidade os aspectos socioculturais nos estudos de usuários. Dentre as teorias deste paradigma podem ser identificadas algumas perspectivas que reconhecem a dualidade da relação entre o cognitivo e o social, como o modelo Everyday Information Seeking (ELIS) de Savolainen (2005), que versa sobre o comportamento informacional na vida cotidiana. As premissas desse modelo, segundo o autor (2005), são que a pessoa busca informações para manter a ordem das estruturas de seu modo de vida, sendo esse modo de vida definido a partir de valores e crenças partilhados, construídos no âmbito do extrato social e econômico onde a pessoa está inserida. Esta ideia baseia-se na constatação de Bourdieu (1984) de que os padrões de vida, os gostos, as noções daquilo que é aceitável e desejável para as pessoas, variam de acordo com sua classe social. As táticas para manutenção do modo de vida utilizando a informação, no entanto, variam cognitiva e psicologicamente.

Conforme Savolainen (2005), são quatro as estratégias de manutenção do modo de vida: a cognitiva positiva, na qual a pessoa utiliza a informação eficazmente para a resolução de problemas; a cognitiva negativa, onde o indivíduo busque e utilize informação de modo sistemático, não há expectativa de que os problemas sejam resolvidos de maneira ótima; a

\begin{tabular}{c|c|c|c|c|c}
\hline (c) RDBCl: Rev. Digit. Bibliotecon. Cienc. Inf. & Campinas, SP & v.17 & $1-27$ & e019010 & 2018 \\
\hline
\end{tabular}




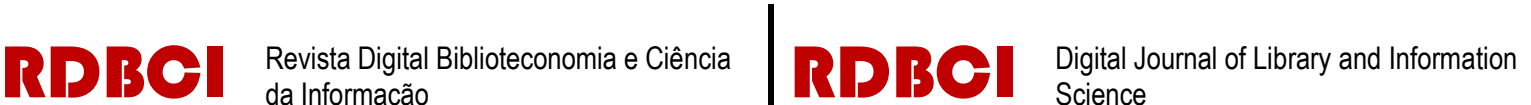

abordagem afetiva defensiva em que há uma visão otimista sobre a resolução dos problemas, embora sejam evitadas situações que impliquem um risco de falha; e a abordagem afetiva pessimista, na qual a pessoa não crê na própria capacidade de resolver os problemas utilizando informação e, portanto, não se engaja nessa busca. Observa-se, porém, que este modelo de comportamento informacional dá mais relevância às preferências de uso da informação em situações que ocorrem na vida fora do ambiente de trabalho, não contemplando as especificidades do contexto laboral.

Outra perspectiva bidimensional dos estudos de usuário, que trata tanto do cognitivo quanto do social, é a Teoria da Cognição Distribuída. Rocha, Paula e Duarte (2016) defendem a Teoria da Cognição Distribuída como um modo de estudar o comportamento informacional em uma teia de relações entre pessoas, ambientes e artefatos de conhecimento. Este é, portanto, outro modo de contextualizar os aspectos cognitivos que os autores situam, não na abordagem alternativa, mas no paradigma social.

Embora exista a divisão entre o paradigma social e a abordagem alternativa, a realidade dos comportamentos de busca e uso da informação denotam que, tanto as necessidades cognitivas individuais, quanto os valores coletivos e sociais, influenciam neste respeito. Assim, Araújo (2010) coloca ainda uma distinta possibilidade para os estudos de usuários: uma abordagem híbrida, que considere tanto elementos da abordagem alternativa, quanto da social. Nessa perspectiva, é coerente raciocinar que uma alternativa para mitigar as lacunas inerentes a cada modelo possa ser encontrada em uma visão multiperspectiva, mais holística, atingida a partir da síntese dos diferentes paradigmas. Para Rocha, Paula e Duarte (2016) não é possível afirmar que uma abordagem de estudos de usuários seja melhor que outra, mas que cada perspectiva deve ser empregada de maneira coerente em cada contexto de pesquisa.

Acredita-se que é importante que se considere a perspectiva do ser humano em relação à informação, isto porque, como já discorrido anteriormente, as máquinas, por não terem consciência, não podem verdadeiramente se beneficiar da informação e assimilá-la do modo que os humanos o fazem. Especialmente quando se considera o contexto organizacional, os seres humanos é que são os verdadeiros elementos impulsionadores do desenvolvimento da empresa, dotados de criatividade e poder de decisão. Nesse contexto, defende-se que é visando os seres humanos que se deve considerar quaisquer estudos de usuários da informação.

\subsection{Modelos de Comportamento Informacional}

A presente subseção visa apresentar sucintamente dois modelos de comportamento informacional que enfatizem o aspecto humano. Spink e Case (2012) explicam que modelos

\begin{tabular}{c|c|c|c|c|c}
\hline (c) RDBCl: Rev. Digit. Bibliotecon. Cienc. Inf. & Campinas, SP & v.17 & $1-27$ & e019010 & 2018 \\
\hline
\end{tabular}


são versões simplificadas da realidade, normalmente representados em forma de diagramas. $\mathrm{O}$ modelo, segundo estes autores, precede a elaboração de uma teoria formal e tem um escopo de aplicação mais restrito que a teoria. Assim, é pertinente apresentar sucintamente um dos vários modelos de comportamento informacional existentes. Os modelos a serem discutidos serão os modelos de Wilson de 1981 (Figura 1), 1996 (Figura 2) e de 2006 (Figura 3). Esses modelos foram selecionados, primeiramente por serem largamente utilizados na CI e áreas correlatas e, em segundo lugar, porque o trabalho de Wilson evoluiu ao longo dos anos, sendo emblemático das mudanças de tendências nos estudos de usuários, segundo Spink e Case (2012).

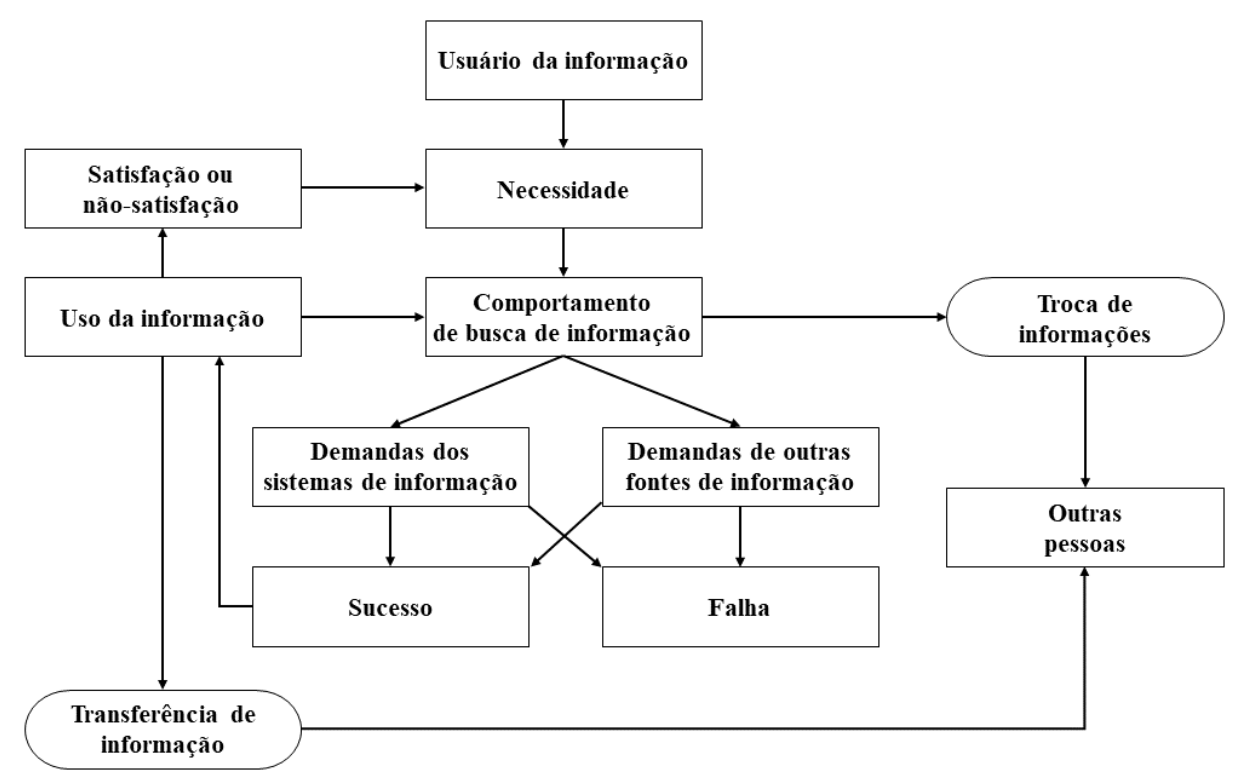

Figura 1. Modelo de Comportamento Informacional de Wilson de 1981. Fonte: Wilson (1999, p. 251, tradução nossa).

Matta (2010) destaca algumas contribuições do Modelo de Comportamento Informacional de Wilson de 1981: o reconhecimento de que a necessidade informacional é secundária e está ligada a necessidades mais básicas, como a fisiológica, a afetiva e a cognitiva; a identificação de barreiras para a satisfação da necessidade informacional, provenientes do próprio usuário, do ambiente ou seu contexto social.

No entanto, Wilson (1997) reconhece que seu Modelo de 1981 não faz nada mais do que prover um mapa para o entendimento do comportamento de busca de informação, desconsiderando quaisquer relações causais envolvidas na busca e uso da informação, falhando ainda em explicitar melhor o papel do contexto nesses dois aspectos. Nessa perspectiva, Wilson cria em 1996 um novo modelo (Figura 2), denominado Modelo de Comportamento Informacional Complexo, sanando os problemas anteriores e incorporando as barreiras supramencionadas como variáveis intervenientes no âmbito da busca de informação. 


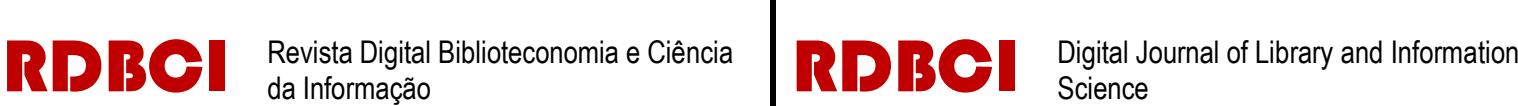

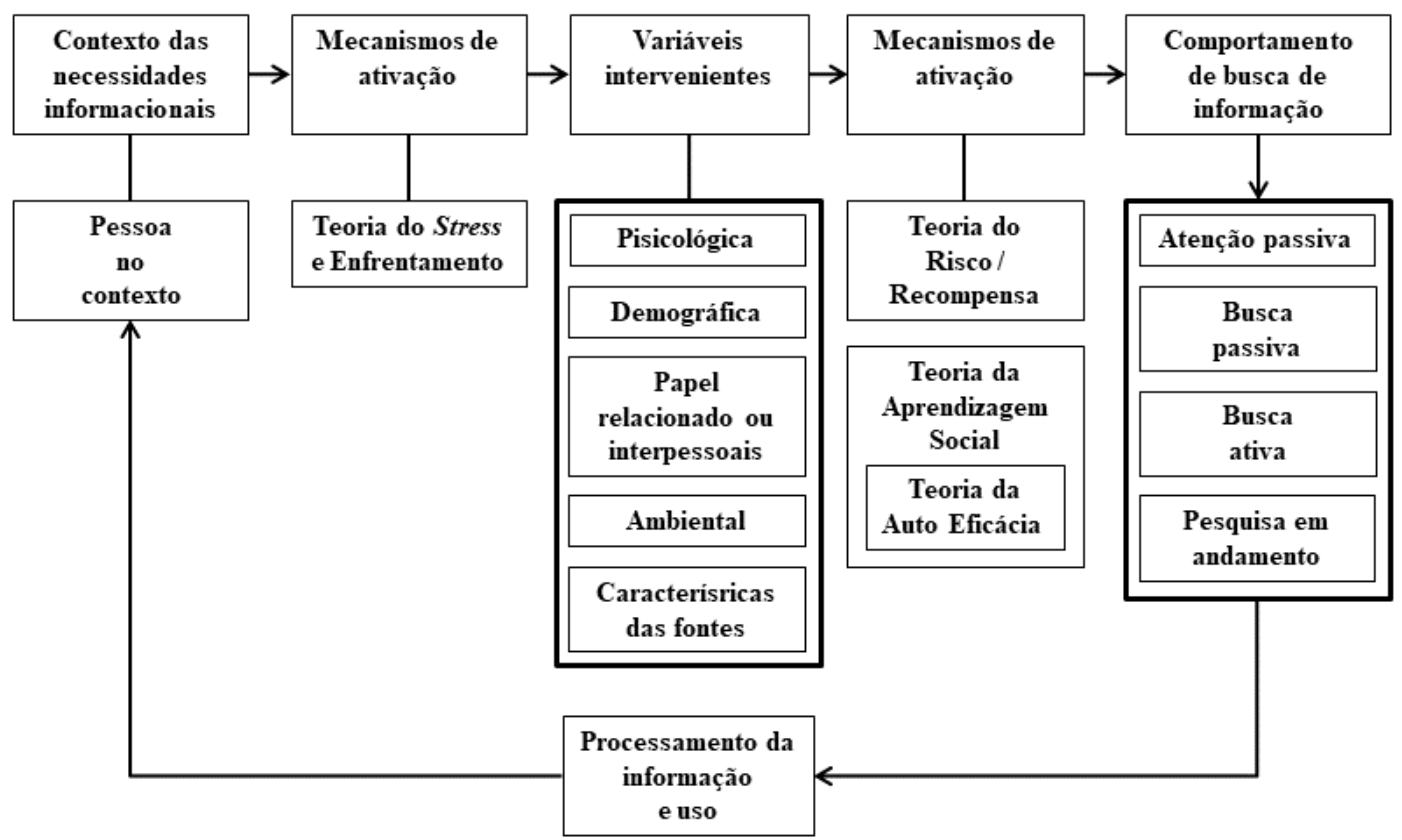

Figura 2. Modelo de Comportamento Informacional de Wilson - 1996. Fonte: Wilson (1997, p. 569, tradução nossa).

Ao segundo Modelo de Wilson (Figura 2) são incorporadas várias teorias de distintas áreas para explicar cada aspecto referente ao comportamento informacional. Segundo o autor supracitado, destacam-se nesse modelo: a Teoria do Stress e Enfrentamento, que determina que necessidades resultarão na busca de informação; a Teoria do Risco e da Recompensa, que explica a preferência por certas fontes de informação; e a Teoria da Auto Eficácia, sobre o nível de confiança do indivíduo em ser bem-sucedido para atingir os resultados satisfatórios com seu comportamento informacional.

O Modelo de Wilson torna evidente as possibilidades de relações interdisciplinares na CI, e como essas contribuições podem ajudar em seu enriquecimento. Observa-se ainda que, mesmo que esse Modelo seja centrado na perspectiva do ser humano, ou cognitivista, ele não se limita a uma visão totalmente alienada do comportamento informacional. $\mathrm{O}$ fato de o modelo considerar o contexto do usuário, os papéis por ele desempenhados e as relações interpessoais, constitui uma espécie de ponte para o paradigma social. Torna-se possível, assim, uma perspectiva mais holística do comportamento informacional.

O terceiro Modelo de Wilson (Figura 3) evidencia o ambiente como um fator determinante e influenciador do comportamento informacional do indivíduo. Estabelece uma relação direta entre a função e o papel que o sujeito organizacional exerce no contexto de trabalho às necessidades psicológicas, afetivas e cognitivas. 


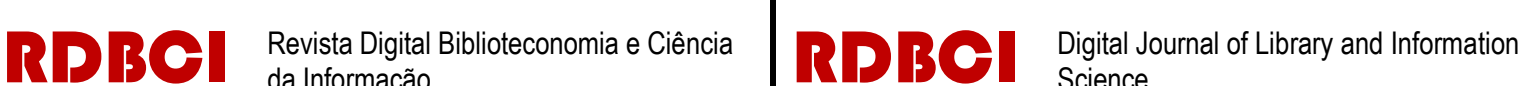

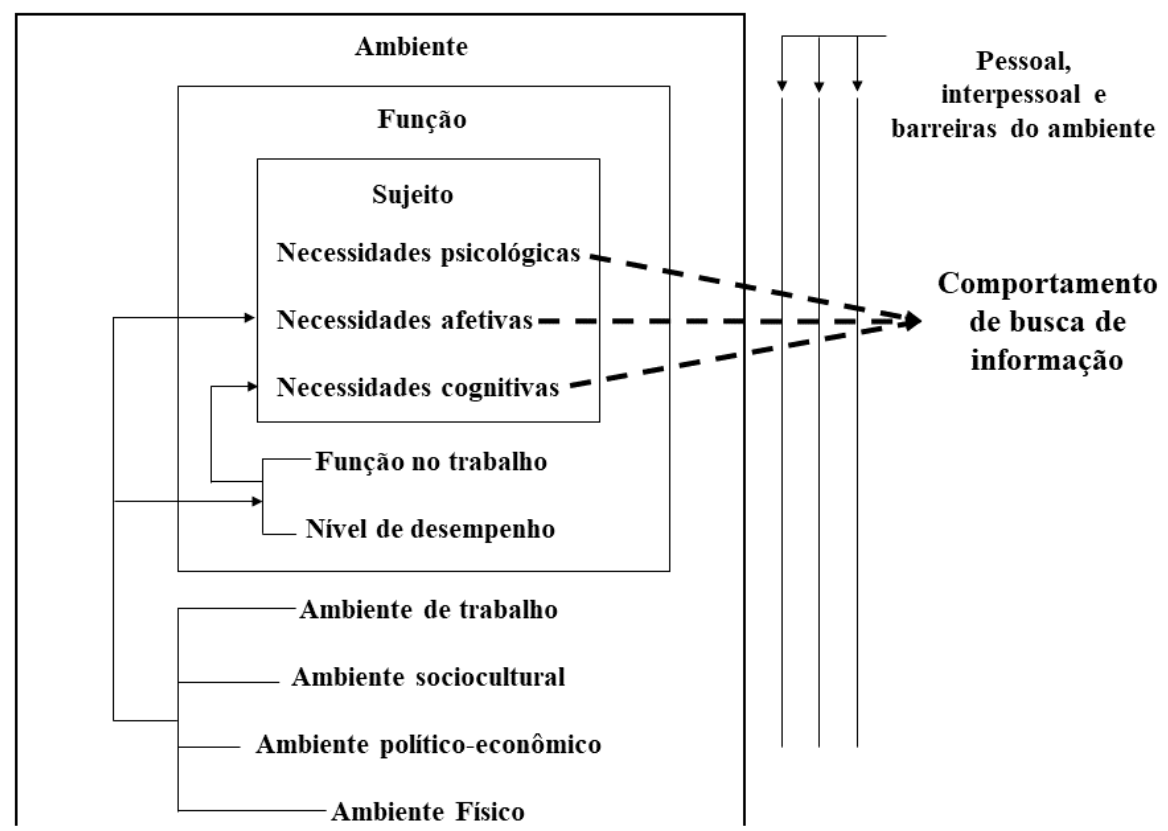

Figura 3. Modelo de Comportamento Informacional de Wilson - 2006. Fonte: Wilson (2006, p. 663, tradução nossa).

Wilson (2006) explica que muitos fatores, além da existência de uma necessidade informacional, influem no comportamento de busca de informação, ou seja, não basta haver uma necessidade informacional para dar início ao processo, pois as barreiras do ambiente podem afetar significativamente o processo.

Assim como o modelo ELIS de Savolainen (2005), discorrido na Seção 3.1, atingiu um equilíbrio entre o cognitivo e o social, sugere-se que o modelo de Wilson (1999) possa ser estendido para contemplar de maneira mais consistente os aspectos sociais do ambiente laboral. Sugere-se empregar o referido modelo juntamente com a análise da cultura organizacional. Para Chiavenato (2003) a cultura organizacional é um conjunto de valores e crenças, o modo coletivamente aceito de pensar e fazer as coisas na organização.

Schein (2007) propõe um modelo de análise da cultura organizacional em três níveis: o dos artefatos, que são os elementos visíveis que representam essa cultura, como o layout físico da empresa, o modo de vestir, o linguajar dos funcionários e afins; os valores casados, que são os valores adotados oficialmente, e as certezas tácitas compartilhadas, que são os valores e crenças arraigados que não estão explícitos. Para o autor (2007), essas certezas tácitas compartilhadas são a real essência da cultura organizacional, que podem ser verificadas ao se contrastar os valores oficialmente adotados, com os artefatos, que denotam a expressão visível das verdadeiras práticas e valores da organização. Assim, tendo sido expostos alguns modelos e abordagens para a análise do comportamento informacional, é pertinente examinar algumas evidências sobre o comportamento informacional dos desenvolvedores de software. 


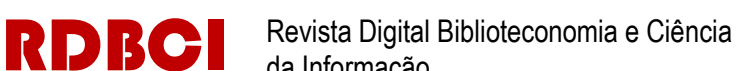 da Informação

\subsection{As Necessidades Informacionais dos Desenvolvedores de Software e cultura organizacional}

Desenvolver software é uma atividade bastante exigente em termos de recursos informacionais, constituindo um contex to em que as mudanças ocorrem constantemente e a um passo acelerado. Salovaara e Tuunainen (2013) afirmam que a constante evolução tecnológica requer dos profissionais de desenvolvimento de software que atualizem seus conhecimentos a todo momento, embora, paradoxalmente, não lhes seja dado muito espaço para essa atualização no âmbito das empresas onde trabalham. Estes autores (2013) afirmam que grande parte das empresas de software adota as chamadas metodologias ágeis de gerenciamento de projetos, que são orientadas para resultados imediatos, nas quais quaisquer práticas que não forem estritamente necessárias para a execução dos projetos são compreendidas como 'perturbações' no fluxo de trabalho. Dessa maneira, ainda na perspectiva destes autores, pouquíssimo tempo é alocado para a elaboração e o compartilhamento de informações e conhecimentos no âmbito das equipes de desenvolvedores de software.

A informação, no contexto do desenvolvimento de software, é requerida para a execução de diferentes tipos de tarefas. Byström e Järvelin (1995) elaboraram um modelo útil de classificação de tarefas com base no nível em que requerem tomadas de decisão, desde as altamente estruturadas, que podem ser automatizadas, até as atividades altamente desestruturadas, que requerem maior esforço cognitivo do sujeito organizacional.

\begin{abstract}
As tarefas automáticas de processamento de informações são a priori completamente determináveis sendo que, em princípio, eles poderiam ser automatizadas [...]. As tarefas normais de processamento de informações são quase completamente determináveis a priori, mas, exigem alguma arbitragem baseada em casos, por exemplo, sobre a suficiência da informação normalmente coletada. [...] As tarefas normais de decisão ainda são bastante estruturadas, mas nelas a arbitragem baseada em casos têm um papel importante. Exemplo: contratação de um empregado ou avaliar a monografia de um estudante. Em tarefas de decisão genuína conhecida, o tipo e estrutura do resultado são conhecidas a priori, mas os procedimentos permanentes para executar as tarefas ainda não surgiram. [...] Tarefas de decisão genuínas são inesperadas, novas e desestruturadas. Assim, nem o resultado, o processo, nem os requisitos de informação podem ser caracterizados de antemão (BYSTRÖM; JÄRVELIN, 1995, p.194-195, tradução nossa, grifo nosso).
\end{abstract}

As tipologias de atividades acima descritas podem ser também usadas para analisar o trabalho dos desenvolvedores de software. Srivatsan et al. (2009) identificaram que 95\% do trabalho dos programadores se concentra nas categorias 'tarefas normais de processamento de informações', 'tarefas normais de decisão' e 'tarefas de decisão genuína conhecida', sendo que, conforme o projeto de software avança, as tarefas vão requerendo maior nível de tomada de decisão. Nesse contexto, a escolha de fontes de informação está diretamente relacionada ao nível de desafio oferecido pelo projeto. Ainda, segundo os autores supracitados, projetos rotineiros apresentam mais 'tarefas normais de processamento de informação', para as quais

\begin{tabular}{l|l|l|l|l|l|}
\hline C RDBCl: Rev. Digit. Bibliotecon. Cienc. Inf. & Campinas, SP & v.17 & $1-27$ & e019010 & 2018 \\
\hline
\end{tabular}




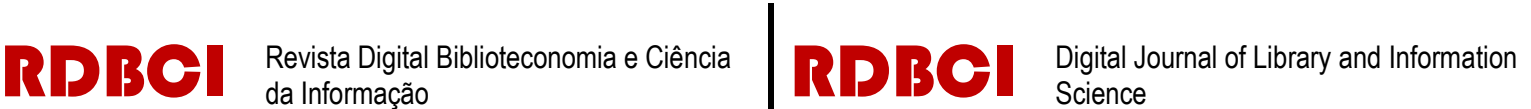

pessoas são mais usadas como fonte de informação, ao passo que projetos inovadores apresentam mais 'tarefas de decisão genuína conhecida', para as quais a Internet é utilizada como fonte de informação.

No entanto, Grzywaczewski et al. (2013) afirmam que o acentuado uso da internet para resolução de problemas de programação se deve, em partes, à indisponibilidade de tempo e barreiras sociais para a comunicação entre colegas programadores. Para os autores, programadores respondem a essa falta de comunicação utilizando práticas de programação oportunistas, que seriam a tentativa de resolução de problemas por tentativa erro, copiando códigos desenvolvidos por outros, disponíveis na Internet. Ainda segundo os autores, as soluções encontradas por meio dessa prática raramente são documentadas para serem futuramente utilizadas por outros, alimentando um ciclo de práticas de programação inadequadas e pouco eficientes. É pertinente, portanto, compreender como se pode modificar as atitudes dos profissionais diante da informação, para que possa haver um fluxo comunicacional mais consistente entre colegas de trabalho e práticas de programação mais consistentes.

Davenport e Prusak (1998) afirmam que a mudança no comportamento informacional deve ser efetuada com uma ação combinada sobre o comportamento e a cultura informacional. Para os autores, enquanto o comportamento diz respeito ao indivíduo, a cultura informacional determina valores, crenças e preferências de um grupo sobre a informação, suas fontes e canais. Crenças e valores compartilhados são justamente as bases da cultura organizacional, como define Chiavenato (2003). Assim, defende-se que a mudança na cultura informacional se dá por meio da mudança na perspectiva da cultura organizacional quanto à relação das pessoas com a informação.

Os processos de mudança cultural variam de acordo com o nível de maturidade da empresa, e se seus fundadores, responsáveis pela criação e difusão da cultura, estão ou não ainda atuantes. Para Schein (2007), em empresas jovens, que ainda têm seus fundadores presentes, os membros abraçam a cultura com mais convicção, por influência desses fundadores. Neste cenário, explica o autor, a mudança cultural pode ser feita colocando na liderança indivíduos que, mesmo abraçando os valores essenciais da cultura, tenham alguns pensamentos e atitudes distintos que se adéquem às mudanças culturais desejadas. Esses líderes serão, portanto, os impulsionadores da mudança, sendo mais facilmente aceitos pelos liderados e fundadores, por concordarem com os princípios básicos da cultura. Em empresas mais antigas, onde a cultura já está criada e os fundadores não estão presentes para promovê-la energicamente, podem ser tomadas medidas mais diretas. Nesta situação, afirma Schein (2007), a mudança pode ser feita por meio de ações educacionais que instruam a adoção de novas práticas, expondo explicitamente os benefícios de sua adoção ou os malefícios de não fazê-lo. 


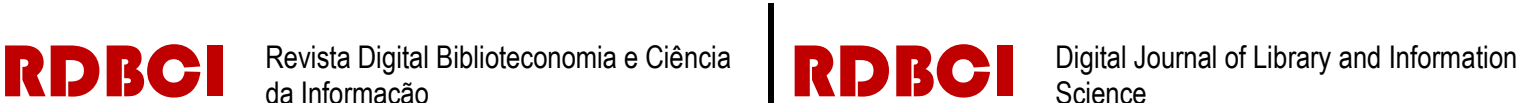

Tendo sido considerados os aspectos comportamentais e culturais, é necessário compreender exatamente em que consistem as tarefas desempenhadas e para que os programadores utilizam a informação de modo mais específico. Essa compreensão possibilita a identificação das necessidades informacionais dos profissionais. Ko, Deline e Venolia (2007) identificaram alguns tipos de atividades que motivam a busca de informação: escrever códigos de programação; compreender e corrigir falhas nos programas; compreender as causas do modo como um programa executa; compreender o propósito e as implicações de mudanças no código; manter-se atualizado sobre o trabalho dos colegas e a evolução do projeto. Para estes autores, os colegas de trabalho são considerados fontes de informação de grande relevância, sendo especialmente importantes para o programador manter-se atualizado sobre o andamento do projeto, compreender o propósito de um código ou o comportamento de execução de um programa.

O papel do ser humano enquanto fonte de informação é exposto por Nonaka e Takeuchi (1997), quando descrevem o processo de socialização que se refere a transmissão do conhecimento proveniente da experiência ou, ainda, no contexto tácito, isto é, de pessoa para pessoa. Os autores supracitados argumentam que existem aspectos desse conhecimento que podem ser difíceis de serem formalizados, ainda que seja um conhecimento estratégico e valioso para a organização. Evidencia-se, portanto, que tanto a comunicação interpessoal quanto as fontes formais de informação são necessárias para o trabalho, de acordo com o tipo e a complexidade da atividade a ser executada.

\section{PROCEDIMENTOS METOdOLÓgicos}

Inicialmente procedeu-se uma revisão bibliográfica visando construir o embasamento teórico do trabalho. Em uma perspectiva multidisciplinar, foram utilizadas obras das áreas de Ciência da Informação, Economia, Filosofia e Computação. Após a construção do referencial teórico, efetuou-se o levantamento de dados acerca da produção científica sobre o comportamento informacional de desenvolvedores de software. O levantamento sobre o tema supramencionado foi efetuado no mês de dezembro de 2018, em três bases de dados: Library and Information Science Abstracts (LISA); Web of Science; e Base de Dados Referenciais de Artigos de Periódicos em Ciência da Informação (BRAPCI). A base LISA, apesar do enfoque em artigos da área de CI, abrange também os campos: Ciência da Computação, Tecnologia da Informação, tecnologias da Internet, Inteligência Artificial, dentre outros ${ }^{1}$. A Web of Science, por sua vez, é uma base de conteúdo variado, abrangendo as mais distintas categorias de áreas do conhecimento, como: 'Ciência da Computação, sistemas da informação', 'Ciência da

\footnotetext{
${ }^{1}$ Disponível em: <https://www.proquest.com/products-services/lisa-set-c.html>. Acesso em: $07 \mathrm{dez} .2018$.

\begin{tabular}{l|c|c|c|c|c}
\hline (c) RDBCl: Rev. Digit. Bibliotecon. Cienc. Inf. & Campinas, SP & v.17 & $1-27$ & e019010 & 2018 \\
\hline
\end{tabular}
}




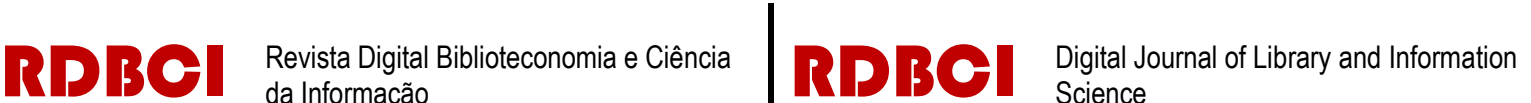

informação e biblioteconomia', dentre outras ${ }^{2}$. Procurou-se, deste modo verificar o volume de trabalhos sobre o tema no âmbito da CI.

Nas bases LISA e Web of Science, os termos utilizados para a busca foram: "(("information behavior" OR "information behaviour" ) OR "user studies") AND ("software developer" OR "programmer")'. O termo para comportamento informacional foi utilizado tanto na variante norte-americana, information behavior, quanto na variante inglesa, information behaviour. O emprego da expressão user studies, ou estudos de usuários, se prestou para aumentar a abrangência da busca, englobando outras perspectivas acerca da relação dos sujeitos com a informação, além do conceito de comportamento informacional. Foram também utilizados tanto o termo software developer, desenvolvedor de software, quanto o termo programmer, ou programador, as duas formas mais comuns de se referir aos profissionais que desenvolvem programas computacionais. O uso de parênteses se mostrou necessário para garantir a ordem correta de leitura da consulta pelo sistema de busca, e a consistência dos resultados, visto que o operador lógico de conjunção, and, tem precedência sobre o operador de disjunção, or. (HASHIMOTO; MORIMOTO, 2010; CLARIVATE ANALYTICS, 2018). Deste modo, garantiu-se que fossem primeiro executadas as instruções nos parênteses para que depois houvesse a sua junção com o operador and.

$\mathrm{Na}$ base BRAPCI a pesquisa '("comportamento informacional" OR "estudos de usuários") AND ("desenvolvedor de software" OR "programador")' apresentou resultados inconsistentes, retornando dezenas de milhares de registros, enquanto que buscas semelhantes nas bases LISA e Web of Science não ultrapassaram a casa das dezenas. Para a obtenção de resultados mais fidedignos, foram realizadas quatro buscas distintas, combinando os elementos da pesquisa original: "estudos de usuários" AND "programador"'; 'comportamento informacional" AND "programador"'; '"comportamento informacional" AND "desenvolvedor de software"'; "estudos de usuários" AND "desenvolvedor de software".'

Inicialmente, foram computadas as quantidades de resultados por base de dados, sendo organizados e expostos em forma de tabela. Em virtude do relativamente reduzido número de resultados retornados em todas as bases de dados consideradas, foi possível analisar os resumos dos trabalhos, para verificar os temas tratados, as perspectivas e paradigmas abordados em relação ao comportamento informacional. Os resultados desta última etapa de análise foram categorizados e organizados também em forma tabular. Por fim, a interpretação dos resultados foi efetuada utilizando aportes teóricos da CI.

\section{RESULTADOS E DISCUSSÃo}

\footnotetext{
${ }^{2}$ Disponível em: <http://imageswebofknowledge.ez87.periodicos.capes.gov.br//WOKRS531OR13/help/pt_BR/WOS/hp_subject_category_term s_tasca.html>. Acesso em: $07 \mathrm{dez} .2018$. (c) RDBCl: Rev. Digit. Bibliotecon. Cienc. Inf. Campinas, SP v.17 $1-27$ e019010 2018
} 
Na presente seção é apresentado o cômputo das quantidades de trabalhos que versam sobre o comportamento informacional dos desenvolvedores de software, ou programadores. Foram utilizadas três bases de dados: LISA, Web of Science e BRAPCI. A Tabela 1 apresenta as quantidades de artigos recuperados a partir da pesquisa pelos termos "(("information behavior" OR "information behaviour") OR "user studies") AND ("software developer" OR "programmer")', nas bases internacionais, como também os resultados na base nacional BRAPCI.

$\mathrm{Na}$ base BRAPCI, foi necessário elaborar uma estratégia distinta, particionando uma expressão de busca maior em quatro pesquisas. Ao se inserir na BRAPCI a expressão de busca '("comportamento informacional" OR "estudos de usuários") AND ("desenvolvedor de software" OR "programador")', apurou-se que a quantidade de resultados retornados estava muito discrepante do que foi obtido nas bases de dados internacionais. Enquanto que a busca de teor semelhante retornou 48 registros na LISA e oito na Web of Science, na BRAPCI foram retornados 20.462 registros. Para constatar a se estariam corretos os resultados, foram efetuadas quatro pesquisas distintas, utilizando os termos: "estudos de usuários" AND "programador"'; 'comportamento informacional" AND "programador"'; 'comportamento informacional" AND "desenvolvedor de software"; "'estudos de usuários" AND "desenvolvedor de software". Todas as buscas acima referidas retornaram zero registros. Infere-se que as possíveis inconsistências da BRAPCI em processar buscas mais complexas se deva ao fato de seu sistema estar ainda em versão beta, como informado, em letras vermelhas, no cabeçalho de sua página eletrônica ${ }^{3}$. Ou seja, infere-se que ainda esteja em processo de aperfeiçoamento.

Tabela 1. Trabalhos sobre comportamento informacional de programadores nas bases de dados internacionais.

\begin{tabular}{ll}
\hline Base de dados & LISA \\
\hline Termos de busca & $\begin{array}{l}\text { ("information behavior" OR "information behaviour" ) OR "user studies") AND } \\
\text { ("software developer" OR "programmer") } \\
\text { Quantidade de resultados }\end{array}$ \\
& 48 \\
\hline Base de dados & Web of Science \\
\hline Termos de busca & TS= ("information behavior" OR "information behaviour") OR "user studies") \\
& AND TS= ("software developer" OR "programmer")
\end{tabular}

${ }^{3}$ Disponível em: <http://www.brapci.inf.br/index.php/res/>. Acesso em: $07 \mathrm{dez} .2018$.

\begin{tabular}{l|l|l|l} 
(C) RDBCl: Rev. Digit. Bibliotecon. Cienc. Inf. & Campinas, SP & v.17 & $1-27$ \\
\hline
\end{tabular}

e019010
2018 


\section{P 190 Revista Digital Biblioteconomia e Ciência

Quantidade de resultados

\begin{tabular}{ll} 
& 8 \\
\hline Base de Dados & BRAPCI \\
\hline $\begin{array}{l}\text { Termos de busca } \\
\text { Quantidade de resultados }\end{array}$ & "estudos de usuários" AND "programador" \\
$\begin{array}{l}\text { Termos de busca } \\
\text { Quantidade de resultados }\end{array}$ & 0 \\
& 0 \\
Termos de busca & "estudos de usuários" AND "desenvolvedor de software" \\
Quantidade de resultados & 0 \\
Termos de busca & "comportamento informacional " AND "desenvolvedor de software" \\
Quantidade de resultados & 0 \\
\hline Total de resultados & $\mathbf{5 6}$ \\
\hline
\end{tabular}

Fonte: Elaborado pelos autores (2018).

Por meio da leitura dos resumos dos trabalhos pôde-se verificar que, apesar de neles constarem os termos de busca, sua maioria versava apenas sobre aspectos de elaboração e análise de código de programação, bem como sistemas informatizados para apoiar as tarefas cotidianas das bibliotecas e/ou seus usuários. A Tabela 2 mostra as categorias temáticas abordadas nos trabalhos recuperados. Os referidos trabalhos foram classificados em dois grupos: os com enfoque mais humanístico e os em que a tecnologia é o assunto preponderante.

Tabela 2. Temáticas abordadas nos trabalhos recuperados.

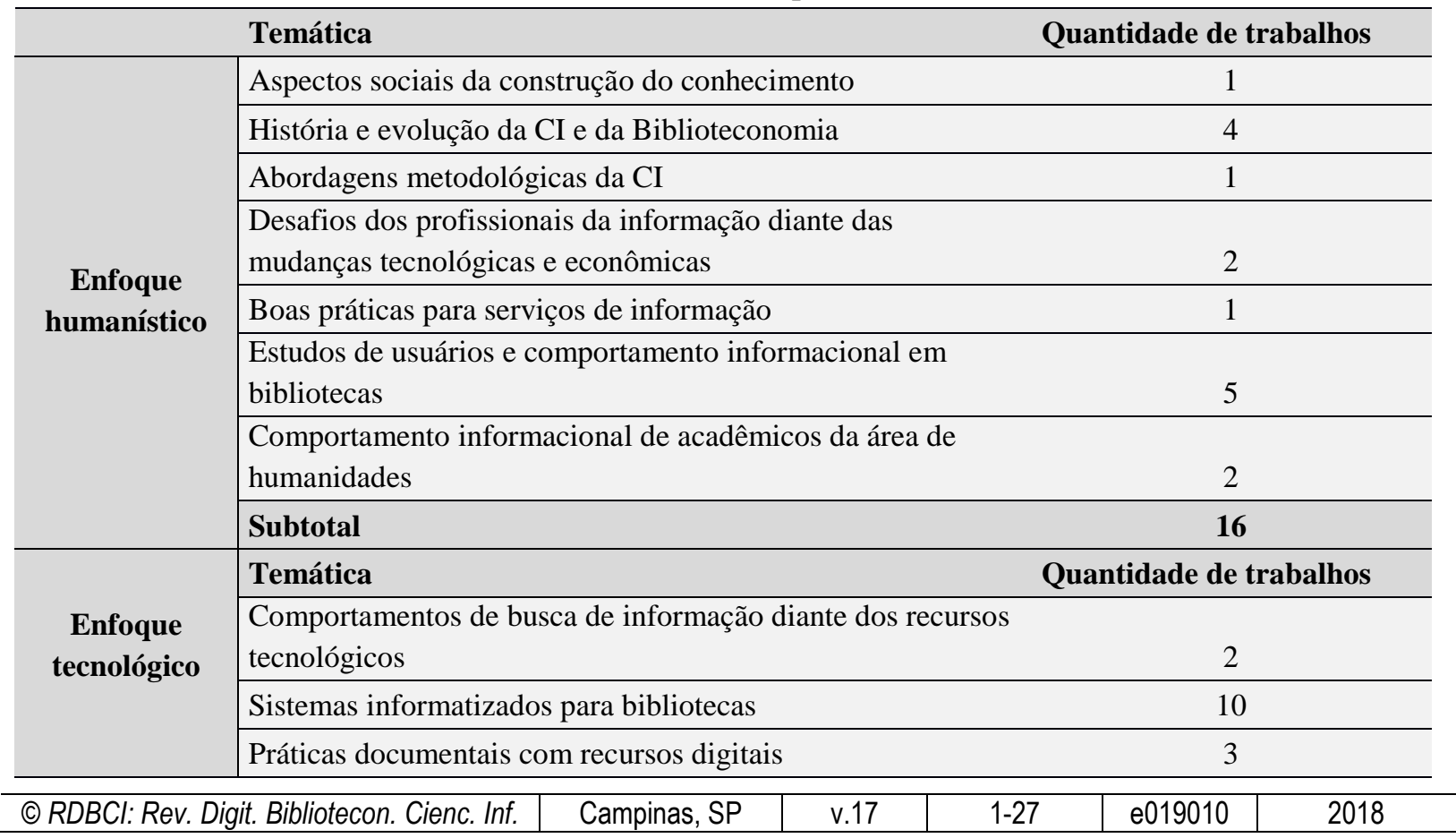




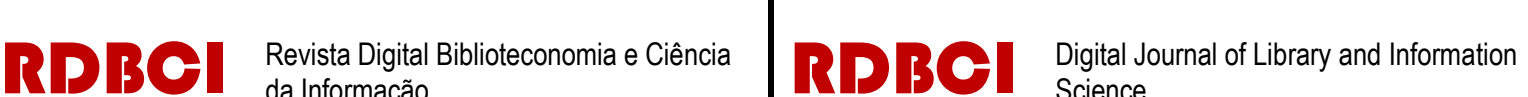

\begin{tabular}{c|lc}
\hline & Bases de dados de publicações científicas e patentes & 4 \\
\cline { 2 - 3 } & Recursos tecnológicos para educação & 1 \\
\cline { 2 - 3 } & Aspectos de usabilidade de software & 3 \\
\cline { 2 - 3 } & Aspectos de elaboração e análise de código de programação & 15 \\
\cline { 2 - 3 } & Inteligência artificial e robótica no cotidiano & 2 \\
\cline { 2 - 3 } & Subtotal & $\mathbf{4 0}$ \\
\hline $\begin{array}{c}\text { Total de } \\
\text { resultados }\end{array}$ & $\mathbf{5 6}$ & \\
\hline
\end{tabular}

Fonte: Elaborado pelos autores (2018).

Verificou-se que, do total de 56 trabalhos recuperados, dois se destacaram por considerarem aspectos da busca e uso de informações pelos profissionais de desenvolvimento de software no âmbito laboral. O trabalho de Grzywaczewski et al. (2013), recuperado da base Web of Science, traz algumas discussões sobre os hábitos de aquisição, uso e compartilhamento de informações dos desenvolvedores de software. Os autores (2013) tratam sobre o desenvolvimento de um sistema de recomendação para auxiliar os programadores na busca informações sobre códigos de software. Segundo Isinkaye, Folajimi e Ojokoh (2015), sistemas de recomendação são aqueles que têm a capacidade de prever que informação provavelmente será útil para um usuário de acordo com o seu perfil, fazendo sugestões a ele e permitindo que o sistema autocomplete os termos de busca. Apesar do enfoque tecnológico, Grzywaczewski et al. (2013) identificam que existem barreiras sociais e de cronograma que dificultam a comunicação entre desenvolvedores de software e os forçam a utilizar a Internet como sua maior fonte de informação, discussão já apresentada anteriormente (Seção 3.3).

É importante salientar que os autores supracitados (2013) tratam de alguns aspectos da relação dos profissionais com a informação sem deixar explícito que abordagem ou paradigma dos estudos de usuários é considerada em seu trabalho. Esta situação deve-se, possivelmente, ao fato de que o trabalho é centrado no desenvolvimento de um recurso tecnológico. O simples uso de soluções tecnológicas para sanar lacunas no comportamento informacional, e problemas comunicacionais, é contestado por Marchand, Kettinger e Rolins (2001), que afirmam que o comportamento informacional eficaz, bem como o compartilhamento eficaz de informação, necessitam de uma cultura organizacional favorável.

O artigo de Sillito, Murphy e De Volder (2008) analisa que perguntas os programadores fazem durante a manutenção e adaptação de código de programação preexistente e como utilizam ferramentas automatizadas de análise para respondê-las, "[...] explorando similaridades, conexões e diferenças entre essas perguntas" (Op. cit. p. 436, tradução nossa). Apesar não ter sido mencionado explicitamente no trabalho acima referido, percebe-se que se trata, de certo modo, de um estudo de necessidades informacionais dos programadores. Estes autores (2008), contudo, restringiram sua análise a elementos do código de programação como

\begin{tabular}{l|l|l|l|l|l|}
\hline C RDBCl: Rev. Digit. Bibliotecon. Cienc. Inf. & Campinas, SP & v.17 & $1-27$ & e019010 & 2018 \\
\hline
\end{tabular}




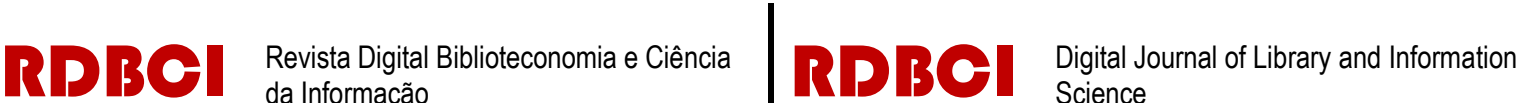

fonte de informação, sendo que questões sobre como abordar as tarefas, ou mesmo sobre o funcionamento das ferramentas de análise de código, não foram consideradas. Também não foram encontradas no trabalho quaisquer referências a modelos ou teorias da CI sobre estudos de usuários, comportamento informacional ou áreas correlatas.

Ademais, verificou-se que vários artigos classificados na categoria 'Aspectos de elaboração e análise de código de programação', exibida na Tabela 2, utilizavam o termo user studies, ou estudos de usuários, porém, com um significado distinto do compreendido na CI. Estes estudos de usuários, de modo geral, são pesquisas experimentais visando verificar a maneira como os sujeitos interagem com as ferramentas tecnológicas, como evidencia o exemplo obtido de um dos trabalhos recuperados:

\begin{abstract}
Nosso estudo de usuário teve como objetivo avaliar a utilidade do Sniff para desenvolvedores em tarefas de programação reais [...]. Projetamos quatro problemas de programação e os atribuímos a um conjunto de usuários [...]. Cada usuário tinha permissão para usar o Sniff para dois dos quatro problemas. Dos dois restantes, eles foram autorizados a usar o Prospector para um problema e o Google Code Search Engine para o outro (CHATTERJEE; JUVEKAR; SEN, 2009, p. 394- 395, tradução nossa).
\end{abstract}

Relevante também é destacar que os artigos recuperados que mencionam a relação dos programadores com a informação no âmbito laboral que constam na base Web of Science não estão na categoria da Ciência da Informação, mas sim nas categorias da Ciência da Computação e engenharia. Os resultados evidenciam uma escassez de trabalhos voltados ao estudo das do comportamento informacional no âmbito do desenvolvimento de software. Esta conclusão está de acordo com a observação de Spink e Case (2012), visto que mencionam que embora os estudos sobre comportamento informacional em categorias ocupacionais se configurem um volume de trabalhos cada vez mais expressivo, a maioria tem se concentrado especificamente em algumas profissões. Estes autores afirmam que esses estudos têm se concentrado mais na área da Saúde e nos estudantes de modo geral, havendo várias categorias profissionais que são parcamente consideradas.

Revelou-se serem poucos os estudos sobre os programadores que não consideram puramente soluções tecnológicas para o provimento de informações necessárias ao trabalho, mas enxerguem o ser humano, contextualizado no meio que o circunda, como protagonista na busca, valoração, aquisição, compartilhamento e uso da informação e do conhecimento. Nessa perspectiva, é essencial que haja um despertar para a realidade de que a tecnologia sozinha não pode satisfazer a contento as necessidades informacionais no âmbito do trabalho, pois é necessário compreender que espécies de informações são requeridas, para que são usadas, de que modo são usadas e as barreiras existentes para a aquisição da informação. É importante ainda que se reconheça, como afirma Wilson (1999), que não só a informação documentada é relevante, mas que as pessoas em si são importantes fontes de informação. As pessoas são não 
apenas fonte de informação, mas criadoras e detentoras de conhecimento acumulado com a experiência de trabalho.

\section{CONSIDERAÇÕES FINAIS}

Em virtude do papel central da tecnologia para a sociedade contemporânea, é necessário considerar de maneira mais atenta as necessidades informacionais dos profissionais que criam essas tecnologias. Como exposto anteriormente, os desenvolvedores de software são profissionais que necessitam adquirir constantemente novas informações e conhecimentos para acompanharem as mudanças que ocorrem em seu meio profissional. No entanto, seu tempo para suprir essa necessidade é escasso. A presente pesquisa demonstrou que são aparentemente poucos os trabalhos acadêmicos que consideram o comportamento informacional dos profissionais desenvolvedores de software. É preciso analisar esse comportamento de maneira holística, considerando tanto a tecnologia, quanto o fator humano, tanto a cognição, quanto o contexto coletivo da cultura organizacional. Este equilíbrio entre diferentes perspectivas busca nada mais do que representar mais fielmente a realidade, que é multifacetada e complexa.

Apenas compreendendo a relação dos profissionais com a informação é possível aprimorá-la, para que o trabalho transcorra de modo mais fluido, para que haja melhores e mais inovadores produtos e serviços. Mesmo que os referidos profissionais estejam imersos na tecnologia, são ainda seres humanos que trabalham em organizações que são estruturadas e que enfrentam desafios de competitividade e sobrevivência de modo bastante semelhante às demais.

As discussões efetuadas no presente trabalho se pautaram exclusivamente no âmbito teórico, utilizando maciçamente trabalhos em língua inglesa sobre as necessidades e o comportamento informacional. Assim, se faz necessário coletar dados empíricos sobre a realidade do comportamento informacional de programadores brasileiros, visto que cada nação tem realidades socioeconômicas peculiares que, possivelmente, interferem no modo de viver e nas relações de trabalho. Sugere-se como trabalhos futuros uma pesquisa sobre o comportamento informacional de desenvolvedores de software no Brasil, efetuando pesquisas de campo e entrevistas no âmbito das empresas. Deste modo, poderão ser evidenciadas tanto as boas práticas informacionais, quanto os problemas enfrentados pelos profissionais em sua relação com a informação. 


\section{REFERÊNCIAS}

ARAÚJO, Carlos Alberto Ávila. Estudos de usuários conforme o paradigma social da ciência da informação: desafios teóricos e práticos de pesquisa. Informação \& informação,

Londrina, v. 15, n. 2, p.23-39, jul./dez. 2010. Disponível em:

<http://www.uel.br/revistas/uel/index.php/informacao/article/view/6485/6995>. Acesso em:

06 fev 2018.

ARAÚJO, Carlos Alberto Ávila. Fundamentos da ciência da informação: correntes teóricas e o conceito de informação. Perspectivas em gestão e conhecimento, João Pessoa, v 4, n. 1, p.57-79, jan./jun. 2014. Disponível em:

<http://periodicos.ufpb.br/ojs/index.php/pgc/article/view/19120/10827>. Acesso em: 06 fev. 2018.

ASSOCIAÇÃO PARA PROMOÇÃO DA EXCELÊNCIA DO SOFTWARE BRASILEIRO.

Relatório Anual. Brasília: Softex, 2015. Disponível em: <http://www.softex.br/a-

softex/booksoftex/ >. Acesso em: 18 nov. 2017.

BOURDIEU, Pierre. Distinction: a social critique of the judgement of taste. Cambridge (MA): Harvard University Press, 1984.

BUSH, Vannevar. As we may think. The Atlantic, jul. 1945. Disponível em: <https://www.theatlantic.com/magazine/archive/1945/07/as-we-may-think/303881/>. Acesso em: 29 nov. 2017.

BYSTRÖM, Katriina; J J̈̈RELIN, Kalervo. Task complexity affects information seeking and use. Information Processing and Management, v. 31, n. 2, p. 191-213, mar./abr. 1995. Disponível em: 〈http://www.sciencedirect.com/science/article/pii/030645739580035R>.

Acesso em: 29 dez. 2017.

CAPURRO, Rafael. Epistemología y ciencia de la información. Enl@ce, Maracaibo, v. 4, n. 1, p. 11-29, jan./abr. 2007. Disponível em:

<http://www.redalyc.org/articulo.oa?id=82340102 >. Acesso em: 29 jan. 2018.

CHATTERJEE, Shaunak; JUVEKAR, Sudeep; SEN, Koushik. SNIFF: A Search Engine for Java Using Free-Form Queries. In: International Conference on Fundamental Approaches to Software Engineering, 12., 2009, York. Proceedings... Berlim: Springer-Verlag, 2009, p. 385- 400. Disponível em: <https://link-springer-

com.ez87.periodicos.capes.gov.br/content/pdf/10.1007\%2F978-3-642-00593-0_26.pdf >. Acesso em: 05 dez. 2018.

CHIAVENATO, Idalberto. Introdução à teroria geral da administração: uma visão abrangente da moderna administração das organizações.7. ed. Rio de Janeiro: Elsevier, 2003 
CLARIVATE ANALYTICS. Principal Coleção do Web of Science - Ajuda. 2018.

Disponível em: $<$ http://images-

webofknowledge.ez87.periodicos.capes.gov.br/WOKRS5272R3/help/pt_BR/WOS/hp_advan ced_search.html>. Acesso em: 16 fev. 2018.

DAVENPORT, Thomas Hayes; PRUSAK, Laurence. Ecologia da informação: por que só a tecnologia não basta para o sucesso na era da informação. São Paulo: Futura, 1998.

DRUCKER, Peter Ferdinand. Sociedade pós-capitalista. 7.ed. São Paulo: Pioneira, 1999.

EREVELLES, Sunil; FUKAWA, Nobuyuki; SWAYNE, Linda. Big data consumer analytics and the transformation of marketing. Journal of Business Research, v. 69, n. 2, p. 897-904, fev. 2016. Disponível em:

<https://www.sciencedirect.com/science/article/pii/S0148296315002842>. Acesso em: 13 dez. 2017.

GLEICK, James. A informação: uma história, uma teoria, uma enxurrada. São Paulo: Companhia das Letras, 2013.

GRZYWACZEWSKI, Adam et al. Supporting information exchange among software developers through the development of collaborative information retrieval utilities. In: International Conference on Computer Supported Cooperative Work in Design, 17, 2013, Whistler. Proceedings... Whistler: IEEE, 2013. Disponível em: $<$ http://ieeexplore.ieee.org/stamp/stamp.jsp?tp=\&arnumber=6580943 > . Acesso em: 16 fev. 2018.

HASHIMOTO, Ronaldo Fumio; MORIMOTO, Carlos Hitoshi. Operadores Lógicos. In: HASHIMOTO, Ronaldo Fumio; MORIMOTO, Carlos Hitoshi. Introdução à Ciência da Computação. São Paulo: Universidade de São Paulo, 2010. p. 32-35. Disponível em: <https://www.ime.usp.br/ hitoshi/introducao/08-OperadoresLogicos.pdf > . Acesso em: 16 fev. 2018.

ISINKAYE, F. O.; FOLAJIMI, Y. O.; OJOKOH, B. A. Recommendation systems: principles, methods and evaluation. Egyptian Informatics Journal, Cairo, v. 16, n. 3, p. 261-273, nov. 2015. Disponível em:

<https://www.sciencedirect.com/science/article/pii/S1110866515000341\#bb0005>. Acesso em: 16 fev. 2018.

JOHNSTON, Chris. Microsoft to buy LinkedIn for \$26bn. BBC: News Business, Londres, 13 Jun. 2016. Disponível em: 〈http://www.bbc.com/news/business-36519766>. Acesso em: 7 dez. 2017.

KAISLER, Stephen. et al. Big data: issues and challenges moving forward. In:

INTERNATIONAL CONFERENCE ON SYSTEM SCIENCES,46., 2013, Wailea (HI).

Proceedings... Wailea (HI): IEEE, 2013. p.995-1004. Disponível em:

$\langle$ http://ieeexplore.ieee.org/stamp/stamp.jsp?arnumber=6479953 >. Acesso em: 13 dez. 2017.

\begin{tabular}{l|l|l|l|l|l}
\hline ○ RDBCl: Rev. Digit. Bibliotecon. Cienc. Inf. & Campinas, SP & v.17 & $1-27$ & e019010 & 2018 \\
\hline
\end{tabular}


KO, Andrew. J.; DELINE, Robert.; VENOLIA, Gina. Information needs in collocated software development teams. In: INTERNATIONAL CONFERENCE ON SOFTWARE ENGINEERING, 29., 2007, Minneapolis. Proceedings... Washington (DC): IEEE Computer Society, 2007. p.344-353. Disponível em:

$<$ http://ieeexplore.ieee.org/stamp/stamp.jsp?tp=\&arnumber=4222596> . Acesso em: $30 \mathrm{dez}$. 2017.

KUHN, Thomas Samuel. A estrutura das revoluções científicas. 5.ed. São Paulo: Perspectiva, 1998.

KUHLTHAU, Carol Collier. Kuhlthau's information search process. In: FISCHER, Karen E.; ERDELEZ, Sandra.; MCKECHNIE, Lynne. (Orgs.). Theories of information behavior. Medford (NJ): Information Today, 2005.

MARCHAND, Donald A.; KETTINGER, William. J.; ROLLINS, John D. Information orientation: The link to business performance. Oxford: Oxford University Press, 2001.

MATTA, Rodrigo Octávio Beton. Modelo de comportamento informacional de usuários: uma abordagem teórica. In: VALENTIM, Marta Lígia Pomim. (Org.). Gestão, mediação e uso da informação. São Paulo: Cultura Acadêmica, 2010. p.127-142.

NONAKA, Ikujiro; TAKEUCHI, Hirotaka. Criação de conhecimento na empresa: como as empresas geram a dinâmica da inovação. Rio de Janeiro: Elsevier, 1997.

POPPER, Karl Raimund. Conhecimento objetivo: uma abordagem evolucionária. São Paulo: EDUSP, 1975.

ROCHA, Janicy Aparecida. Pereira.; PAULA, Cláudio Paixão Anastácio; DUARTE, Adriana Bogliolo Sirihal. A cognição distribuída como referencial teórico para os estudos de usuários da informação. Informação \& Sociedade: Estudos, João Pessoa, v.26, n.2, p.91-105, maio/ago. 2016. Disponível em:

<http://www.brapci.inf.br/index.php/article/download/46579>. Acesso em: 7 jan. 2017.

SALOVAARA, Antti; TUUNAINEN, Virpi. Kristiina. Software developers' online chat as an intra-firm mechanism for sharing ephemeral knowledge. In: INTERNATIONAL

CONFERENCE ON INFORMATION SYSTEMS, 34, 2013, Milão. Proceedings... Milão:

ICIS, 2013. p.3505-3523. Disponível em:

<https://aisel.aisnet.org/cgi/viewcontent.cgi?article=1141\&context=icis2013>. Acesso em: 29 dez. 2017.

SARACEVIC, Tefko. Information Science. Journal of the American Society for

Information Science. v. 50, n.12, p. 1051-1063, out. 1999. Disponível em: $<$ http://onlinelibrary.wiley.com/doi/10.1002/(SICI)1097-4571(1999)50:12\%3C1051::AIDASI2\%3E3.0.CO;2-Z/epdf>. Acesso em: 17 nov. 2017. 
SAVOLAINEN, Reijo. Everyday life information seeking. In: FISHER, Karen. E.; ERDELEZ, Sandra; MCKECHINE, Lynne. (Org.). Theories of information behavior. Medford (NJ): Information Today, 2005. P. 143-148.

SCHEIN, Edgar Henry. Guia de sobrevivência da cultura corporativa. 2 ed. Rio de Janeiro: José Olympio, 2007.

SILLITO, Jonathan; MURPHY, Gail C.; DE VOLDER, Kris. Asking and answering questions during a programming change task. IEEE Transactions on Software Engineering, v. 34, n. 4, p. 434- 451, jul./ago. 2008. Disponível em: < https://ieeexploreieee-org.ez87.periodicos.capes.gov.br/stamp/stamp.jsp?tp=\&arnumber $=4497212>$. Acesso em: 05 dez. 2018.

SPINK, Amanda.; CASE, Donald Owen. Looking for information. 3.ed. Bingley: Emerald, 2012.

SRIVATSAN, V. R. et al. Systems developers define their own information needs. In: AMERICAS CONFERENCE ON INFORMATION SYSTEMS, 15., 2009, São Francisco. Proceedings... São Francisco: Association for Information Systems, 2009. p.5012-5022. Disponível em: <https://www.researchgate.net/profile/Sandeep_Purao/publication/220893761_Systems_Dev elopers_Define_their_Own_Information_Needs/links/Ofcfd51110864b236d000000/SystemsDevelopers-Define-their-Own-Information-Needs.pdf>. Acesso em: 29 dez. 2017.

WILSON, Thomas Daniel. Information behaviour: An interdisciplinary perspective. Information Processing and Management, v.33. n.4, p.551-572, Jul. 1997. Disponível em: <https://doi.org/10.1016/S0306-4573(97)00028-9>. Acesso em: 7 dez. 2017.

WILSON, Thomas Daniel. Models in information behaviour research. Journal of Documentation, v.55, n.3, p.249-270, Jun. 1999. Disponível em: <https://doi.org/10.1108/EUM0000000007145>. Acesso em: 07 dez. 2017.

WILSON, Thomas Daniel. On user studies and information needs. Journal of Documentation, v.62, n.6, p.658-670, 2006. Disponível em: <https://doi.org/10.1108/00220410610714895>. Acesso em: 07 dez. 2017. 